\title{
What happens during a teaching-learning process of martial arts and combat sports with novice - A case-study focused on the joint activity organization analysis
}

\author{
Bruno AVELAR-ROSA* \& Víctor LÓPEZ-ROS \\ University of Girona (Spain)
}

8th IMACSSS International Conference Abstracts, Viseu (Portugal), October 10-12, 2019

Type: Oral communication

\begin{abstract}
Semiotic devices are relevant tools to study the teaching-learning process according to the constructivist perspective, which supports several of the game-centered approach models. Even not being included in the generality of these models, martial arts and combat sports have a clear potential to be developed according to these models. Following this, it was settled a didactic sequence based on the fighting knowledge development through the learning of a striking and a throwing skill. A pragmatic discourse analysis was made and specific forms of joint activity organization, called segments of interactivity, were identified. Inside these segments, several patterns were registered considering their main function and format of interaction. The segments of interactivity of activity organization and guided practice constituted both the bigger part of the time and total number of segments, which suggest that the learning processes should be understood inside of their scope. This way, looking for the activity organization, the predominance of the patterns related with "execution" evolve according with the appropriation of the contents, while the "function" patterns seem to be more relevant when it is proposed a new or more complex task. By the other hand, the results related to guided practice segments remark the importance of the one-to-one interactions between the teacher and the apprentice within the whole classes situation. These results show the singularity of every teaching-learning process in terms of the progressive transfer of control and responsibility from the teacher to the apprentice and the simultaneous establishment of an increasingly rich network of shared meanings between these agents.
\end{abstract}

Keywords: Martial arts; combat sports; constructivism; interactivity; activity organization; guided practice; fighting knowledge.

\section{Introduction}

The sociocultural constructivist perspective of teaching-learning (T-L) is based on the acknowledgement that any educative process is constituted by different forms of joint activity organization (JAO), where teacher and learners interact around a certain content. From this point of view, knowledge is an individual process built in the scope of this interaction between these agents, through whom a continuous negotiation happens. This way, teacher, apprentices, and content constitute an indivisible unit of activity, designated as interactive or didactic triangle (Amade-Escot, 2000), that evolves through the length of the T-L process. For seeking the understanding of how the knowledge construction occurs and the way in which the teacher influences the process of learning by the apprentices, it is essential, thus, to analyse the interactivity, which means, how the elements of the didactic triangle are articulated and how this relation evolves.

The influence of the teacher in the T-L process is based on his role as a hierarchic agent. The teacher acts being a guide on the knowledge construction process developed by each apprentice, which is, in our study, related to the concept of zone of proximal development (ZPD) proposed by Vygotsky (1978). Generically, this concept represents the difference between what the apprentice can solve himself (e.g. solve a task) and what he manages to do with the help of a more expert

*Email: bruno.ibe@gmail.com 
person when solving the task. In this process, the negotiation and the intersubjectivity on the individual development take a fundamental role, which are stimulated by the external intervention of the expert who guides and helps the knowledge construction like it is proposed by Wood, Bruner, and Ross (1976) with the "scaffolding" metaphor. This metaphor refers to the structuring of the pedagogic help: first the teacher gives support with greater intensity and regulation, and then this intervention is progressively withdrawn along the evolution of apprentice learning, who becomes more and more autonomous. This greater autonomy manifests the progressive transfer of control and responsibility from the teacher to the apprentice, which also occurs with the establishment of an increasingly rich network of shared meanings between these agents. These two processes, known as mechanisms of educational influence, are developed through specific didactic devices that take place in the ZPD and where the use of semiotic resources is essential (Coll, Onrubia, \& Mauri, 2008).

Within the physical education and sport context, the games-centered approach (GCA) models of teaching/coaching, where belongs the integrated technical-tactical model (IT-TM) proposed by López-Ros and Castejón (2005), are those who more emphasize the importance of the interaction between the teacher and the apprentices and the use of semiotic resources like questions, recapitulations, labels or debates, as a way of favouring a more significant learning (e.g. Wright \& Forrest, 2007). Nevertheless, the GCA models don't specifically include the martial arts and combat sports (MA\&CS) and the studies that explicitly related them are scarce or eminently theoretical. This way, considering their structural and functional characteristics, particularly in terms of the technical-tactical complexity, the MA\&CS seem an adequate context for applying a GCA approach and for analysing its learning-process dynamics through the lens of the constructivist approach.

Thus, the purpose of this study was to analyse the JAO in a didactic sequence (DS) of a general approach of MA\&CS with novices, seeking for analyse how the process of transfer of the control and responsibility from the teacher to the apprentice occurs and how it is established an increasingly rich network of shared meanings. This DS was created and applied following the guidelines of the IT-TM and the "fighting knowledge" development approach proposed by AvelarRosa et al. (2015).

\section{Methodology}

This research, developed from an interpretative, naturalistic and qualitative perspective, is a case study (considering the DS as an intrinsic case). The DS was carried out under the form of participant observation, with pupils of the $4^{\text {th }}$ year of the Portuguese primary school $(n=12)$, constituted by 10 sessions of 60 minutes, which were recorded in audio-visual format, and built around the learning of two tasks related with striking and throwing skills. The actions and all verbal interactions between teacher and apprentices along the DS were recorded and observed. In order to analyse data, it was mainly used discourse analysis based on pragmatics framework. The interactions produced define different segments of interactivity (SI), which are particular forms of JAO. In each type of SI, teacher, apprentices and contents interact in a coherent and differentiated way in relation to other moments and contexts of the DS. Internally to every SI, specific interpersonal behaviour patterns were analysed, having been defined according to their instructional function and specific format of interaction. A performance assessment tool was also applied along the DS in order to evaluate the learnings and the development of the fighting knowledge.

\section{Results and Discussion}

Seven types of SI were identified: activity organization (SIAO), guided practice (SIGP), directive practice, observed practice, discussion, recapitulation, and transition. Although of the particularities of the T-L process, these SI are coherent with other studies developed in other educational and sports environment (cf. Llobet-Martí, López-Ros, \& Vila, 2018). However, unlike these studies: a) there was no decrease, in time and number, of the SIAO; and b) there was no increase, in time and number of the SIGP throughout the DS, which would suggest, more explicitly, the knowledge appropriation by the apprentices and a lesser need of teacher intervention. According to the positive results of learning obtained though the performance assessment made, it was required to analyse the interactivity at a deeper level. This way, it was considered the need of 
developing a micro-analysis of the SIAO and SIPG, which represented both around $60 \%$ of the total number of SI identified and $80 \%$ of the DS time.

Considering the SIAO patterns identified, about $40 \%$ of them were related with "function" (rules) and "execution" (content), but while the first one was composed mainly by patterns of explanation and command ordered by the teacher, the second was composed by questions and proposals stimulated by the teacher, being also possible to observe the increasing of the "execution" patters between the session one and eight at the same the time that the "function" patterns decreased. This may reveal a progressive lower attention to the appropriation of the rules along the DS and a further awareness of the contents that are supposed to be learnt within. At the last two sessions, this proportion changed again, following the introduction of new and more complex tasks.

Looking to the SIGP patterns identified, it is possible to observe that around $40 \%$ of them were directed to an apprentice/pair and about of $35 \%$ were directed to the whole class, but while the patterns developed between the teacher and an individual apprentice/pairs were mostly composed by "execution" (content) commands, the patters of interaction that are strictly directed to the whole class were mostly composed by commands about "function" (rules) and "organization" (space). These results show the importance of the individual interactions between teacher and apprentice within the class for learning purposes.

\section{Conclusion}

Results showed that, even not being explicit through the evolution of the JAO's structure and its respective SI, the process of progressive transfer of the control and responsibility from the teacher to the apprentice was observed through an analysis at a deeper level, such as looking at the patterns of instructional functions along the T-L process and the forms of interaction developed during the apprentices' practice, which greatly depends of the tasks structure. Complementary, it was also possible to observe some major indicators related with the meanings that were shared between the teacher and the apprentices over the DS, once it was shown that the teacher influenced the apprentices embedded in the practice formats they were involved and using different semiotic devices according if they were in a one-to-one interaction or in a whole class situation. Thus, there was a close relationship between the structure of the interaction and the evolution of the instructional functions sense, which reveals the occurrence and development of the mechanisms of educational influence and the consequent learning of the contents aimed for the apprentices.

\section{References}

Amade-Escot, C. (2000). The contribution of two research programs on teaching content: "pedagogical content knowledge" and "didactics of physical education". Journal of Teaching in Physical Education, 20(1), 78-101. doi: 10.1123/ipe.20.1.78

Avelar-Rosa, B., Gomes, M.S.P., Figueiredo, A., \& López-Ros, V. (2015). "Fighting knowledge" characterization and development: contents of an integrated model for teaching martial arts and combat sports. Revista de Artes Marciales Asiáticas, 10(1), 16-33. doi: 10.18002/rama.v10i1.1501

Coll, C., Onrubia, J. \& Mauri, T. (2008). Supporting learning in educational context: the exercise of educational influence and the analysis of teaching. Revista de Educación, 346, 33-70.

Llobet-Martí, B., López-Ros, V., \& Vila, I. (2018). The analysis of interactivity in a teaching and learning sequence of rugby: the transfer of control and learning responsibility. Physical Education and Sport Pedagogy, 23(1), 84-102. doi: 10.1080/17408989.2017.1341472.

López-Ros, V. \& Castejón, F.J. (2005). Integrated teaching of technical-tactic sports during school years. Apunts. Educació Física i Esport, 79, 40-48.

Vigotsky, L.S. (1978). Mind in Society: The development of higher psychological processes. Cambridge MA: Harvard University Press.

Wood, D., Bruner, J.S., \& Ross, G. (1976). The role of tutoring in problem-solving. Journal of Child Psychology and Psychiatry, and allied disciplines, 17, 89-100. doi: 10.1111/i.14697619.1976.tb000381.x

Wright, J., \& Forrest, G. (2007). A social semiotic analysis of knowledge construction and games centred approaches to teaching. Physical Education and Sport Pedagogy, 12(3), 273-287. doi: $\underline{10.1080 / 17408980701610201}$ 